\title{
Performance analysis of B2B and B2C companies in Northern Macedonia and Serbia
}

\author{
Vedat Asipi, Benjamin Duraković* \\ Industrial Engineering, International University of Sarajevo, Bosnia \\ *..Corresponding author: bdurakovic@ius.edu.ba \\ (C) The Author(s) \\ 2020. \\ Published by \\ ARDA.

\begin{abstract}
(The purpose of this paper is to analyze and compare two different busimess models

The purpose of this paper is to analyze and compare two different business models called business to business and business to consumer. The first model -business to business or B2B is defined as the transfer of goods and services between businesses or firms without interference of consumer. The second model, business to consumer or $\mathrm{B} 2 \mathrm{C}$ is customer oriented in which the goods and services are sold immediately to customers in the market. This research focuses on the performance of these two business models in North Macedonia and Serbia. Our analysis tries to provide information regarding the countries' development on different sectors within B2B and B2C models that are affected by specific indicators such as net salaries, total employment level, investment and exports, and research\&innovation. Furthermore, besides analysis of these indicators separately for each country, the paper will show the results and compare the performance differences among listed developing countries.
\end{abstract}

Keywords: B2B, B2C, Innovation, Net salaries, Total employment, Investment, Exports

\section{Introduction}

In today's business world firms have to face with a dynamic market, but not just only that, they have to know what is the right business model that will affect the performance at the end of the day. With the use technology, companies realized that it is necessary to have an innovative business model in order to have better interaction with the customers [1]. 
Innovation is defined as the process which transforms ideas that are generated as inputs into outputs and it plays a crucial role in increasing customer value and competitive advantage [2]. Moreover, some suggested innovation, as the life blood of the businesses, determines its survival and winning [3]. Supply chain is defined as set of activities in the organization that includes parties involved in delivering goods and services from the input until the output - customer, such as manufacturer, suppliers, transporters, warehouses and retailers [4].

Supply chain management is vital for the companies to sustain their competitive advantage in business models [5]. A strong supply chain which will fulfill a customer request is very important for both B2B and B2C business models. B2B business models are generally for the big corporations and these are the firms that market directly to other businesses and governments including suppliers, distributors and agencies rather than to individual customers [6]. The second model, B2C refers to the process of selling goods and services directly between a business and consumers who are the end users of these products or services [7].

The history of Total Quality Management is made up to four phases which are: quality inspection, quality control, quality assurance and Total Quality Management [8]. The idea of the Total Quality Management is that its principles should be applied at every department of the organization, every level and every stage of it [8]. In the opinion of Demin, business problems occur within the management activity, and statistical tools and methods are those which help to identify the starting point of the obstacles [9]. So, it is very important for business models to apply the tools and principles of the Total Quality Management in order to prevent any drastically high costs that might occur later in the company later.

This research aimed to analyze the performance of B2B and B2C companies in Albania, Bulgaria, Montenegro, North Macedonia and Serbia with the aim to identify which business models will bring more benefit to the considered countries, by examining sectors of activity such as Agricultural, Construction, Energy, Manufacturing, and Mining. In order to determine the result of these sectors, companies are classed into two categories. The first category is comprised of B2B firms, meaning companies that generally produce semifinished products that will be used in supply chains. Researches conducted in these areas in order to show the fundamental importance of B2B and B2C exchange in management operations showed that particularly, B2B transactions occurs in supply chain process [10][11]. For instance, an aerospace company makes many B2B transactions such as buying engine, aircraft tires and seats before the final transaction takes place. The second category consists of B2C companies, in which goods and services are immediately sold to the consumers for consumption, whereas in some cases the research proved that $\mathrm{B} 2 \mathrm{C}$ showed more successful for both country and its citizens [31]. Electricity, education, internet are some examples of business-to-consumer model.

There are many researchers tend to focus on production and innovation in business institutions [12]. According to Anthony, besides being focused on product or services, now innovations increasingly use on developing business models that enhance its center competency [13]. Damanpour and Schneinder stated that innovation is being studied in many disciplines and de-fined from different perspectives [14]. In addition to this, innovation is studied by scholars, as the key success factor for the companies' sustainability performance by many scholars [15][16][17][18]. Within the business models, innovation can be categorized into three ways which are technology-push, disruptive innovation and demand-full approach. Also, business model can itself characterize a form of innovation [19], without changing the substance of products and services' delivery and by editing the internal operations of the company [20]. Technology-push approach can be found in larger organizations which allow the organization to take an advantage by positioning itself as the first mover firm in the market [20]. Another way is known as disruptive innovation which refers to developing initiatives that helps the business to sustain leadership in the market such as editing the existing products or services and providing a secondary product to the market [21]. Lastly, the third way of innovation is so-called demand-pull approach in which the businesses shall consider the re-evaluation in order to meet the needs of customers and business environments [22]. However, there is a lack of studies conducted to note the role of B2B and B2C companies according to the sectors.

This study conducted to examine Agricultural [AGRI], Construction [CONSTR], Energy [NRG], Manufacturing [MFG], and Mining [MIN] sectors. Variables that are going to be measured within these sectors 
are as following: exports, employment, net salaries, and investment. Observed data is measured on 8 years average for North Macedonia, and Serbia.

Therefore, the following hypotheses were tested for the countries mentioned above:

- $\mathrm{H} 1: \mathrm{B} 2 \mathrm{C}$ is better-paid than $\mathrm{B} 2 \mathrm{~B}$

- $\mathrm{H} 2: \mathrm{B} 2 \mathrm{C}$ has lower employment rate than $\mathrm{B} 2 \mathrm{~B}$

- H3: B2C companies are more successful B2B

- H4: B2C companies' investments are higher than B2B

The importance of this paper is to detect the problems in the considered countries and within their local labor markets and discussing possible solutions. One of the biggest problems these countries are facing is the braindrain, which is increasing across and affecting the labor market in a negative way [23]. Also, another subject of this paper is to clarify which model, either B2B or B2C is more successful and tempting in the workforce. Skilled people are leaving the countries, especially youth, for better working conditions and salary. For instance, according to EPIK (European Policy Institute of Kosovo) reports, Albania is the leading country in the Balkans with 1.25 million people leaving the country in the last 10 years. Results also estimated that in the same period 258.000 people moved out of North Macedonia while Montenegro had the lowest emigration numbers which is almost 36.000 people. Therefore, there is a need for B2B and B2C companies to be more attractive for local workers in these countries.

As restriction, throughout the research we have faced may obstacles, such limited data of statistical agencies, related to different countries, years and sectors. Thus, each data was analyzed based on year average for each country.

\section{Research method}

Hypothesis testing is chosen as a research method for our analysis. T-test helps us to identify if hypothesis is failed to reject or rejected.

\section{$2.1 \quad$ T-test}

$T$-test is used to determine whether statistical data is significant between two sample means. In our study we used independent samples $t$-test to compare two different groups in which the data of two populations are not related to each other. Independent samples t-test will tell us whether there is a significance difference between $\mathrm{B} 2 \mathrm{~B}$ and $\mathrm{B} 2 \mathrm{C}$, or not. Observed $t$-test is determined with the following formula:

$$
t_{o}=\frac{\bar{x}_{1}-\bar{x}_{2}-\Delta_{0}}{\sqrt{\frac{s_{1}{ }^{2}}{n_{1}}+\frac{s_{2}^{2}}{n_{2}}}}
$$

where, $t_{o}$ is observed $t$-test which means the data that we will observe during the statistical testing, $\bar{x}_{1}$ and $\bar{x}_{2}$ represent the average value of both groups, $\Delta_{0}$ represents the hypothesized mean difference, $s_{1}$ and $s_{2}$ stands for the variances of two groups, and the sample size of the both groups is represented by $n_{1}$ and $n_{2}$.

When conducting two sample t-test the first step is to determine the hypothesis, which are null and alternative hypothesis [24]. As Marilyn and Theresa stated, null hypothesis is labelled as $H_{0}$ which indicates that there is no statistically significant difference between two sample averages, while alternative hypothesis which is labelled as $H_{1}$ shows that there is statistically difference between two sample averages [25]. The following step is to state the significance level, $\alpha$ which is the maximum probability that is allowed for the rejection of the null hypothesis [25]. The third step is computing the observed t-test, which tells us whether we should accept or reject the null hypothesis [25]. After comparing the value from observed t-test and the one taken from the statistical $t$ table we make conclusions based on these values [25]. In general, after the calculation of the test 
statistic $\left(t_{o}\right)$, if the value of $t_{c r}$ is greater than the value of $t_{o}$ we conclude that there is enough statistical difference between the groups.

In our study, the hypothesis that we have tested using t-test method is listed below:

- $\mathrm{H} 1: \mathrm{B} 2 \mathrm{C}$ has is better-paid salary than $\mathrm{B} 2 \mathrm{~B}\left(\mu_{1}>\mu_{2}\right)-$ Net salaries

- $\mathrm{H} 2: \mathrm{B} 2 \mathrm{C}$ has lower employment rate than B2B $\left(\mu_{1}>\mu_{2}\right)$ - Employment

- H3: B2C companies are more successful B2B $\left(\mu_{1}>\mu_{2}\right)$ - Exports

- H4: B2C companies' investments are higher than B2B $\left(\mu_{1}>\mu_{2}\right)$ - Investment

where, $\mu_{1}$ represents the $\mathrm{B} 2 \mathrm{C}$ business model, and $\mu_{2}$ is meant for the $\mathrm{B} 2 \mathrm{~B}$ business model.

\subsection{Analysis of variance - ANOVA}

ANOVA or Analysis of Variance is used as the second method for our research to calculate the statistical data. It's as similar as t-test, but the difference between them is that in t-test we analyze whether statistical data is significant between two sample means. However, ANOVA is used to calculate and analyze whether statistical data is significant for more than two groups or treatments [26].

In the following we will present the steps and formulas for calculating the ANOVA.

Firstly, mean of squares due to treatments is computed which is denoted as MSTR, and its general formula is shown below:

$$
M S T R=\frac{S S T R}{k-1}
$$

The numerator SSTR is called the sum of squares due to treatments and in the denominator of equation, k-1, represents the degrees of freedom related with SSTR [27]. SSTR is calculated as following:

$$
S S T R=\sum_{j=1}^{k} n_{j}(\bar{x}-\overline{\bar{x}})^{2}
$$

where, $n_{j}$ is the number of observations for treatment $\mathrm{j}, \bar{x}$ is the average for treatment $\mathrm{j}$ and $\overline{\bar{x}}$ represents the overall average which is the sum of all observations divided by the total number of observations [27].

Secondly, we calculate sample variance within treatments in which the estimate of it is called mean square due to error or MSE [28], which is calculated with the following formula:

$$
M S E=\frac{S S E}{n_{T}-k}
$$

SSE is known as sum of squares due to error in equation (5), and $n_{T}-k$ is the degrees of freedom related to the SSE.

SSE is calculated with the formula below:

$$
S S E=\sum_{j=1}^{k}\left(n_{j}-1\right) s_{j}^{2}
$$

where, $n_{j}$ is the number of observations for treatment and $s_{j}^{2}$ is the sample variance for treatment. 
Finally, we can calculate $\mathrm{F}$ statistic with the $k-1$ degrees of freedom in the numerator and $n_{T}-k$ in the denominator:

$$
F_{o}=\frac{M S T R}{\mathrm{MSE}}
$$

After the calculation of the test statistic $\left(F_{o}\right)$ in equation (6), if the value of $F_{c r}$ (the value from $F$-distribution table) is greater than the value of $F_{O}$ we conclude that there is at least one significant difference between the groups, which means the mathematical model is significant.

\subsection{Multiple linear regression model}

Multiple regression method was used to analyse and discover whether there is a relationship between response (dependent) variables denoted by $\mathbf{y}$, and explanatory (independent) variables denoted by $\mathbf{x}_{\mathbf{1}}, \mathbf{x}_{\mathbf{2}}, \ldots, \mathbf{x}_{\mathbf{n}}[29]$. By applying assuming different hypothesis, we have used multiple regression to understand whether independent variable(s) are significant contributor to the dependent variable. Multiple linear regression model can be stated as following:

$$
y=\beta_{0}+\beta_{1} x_{1}+\beta_{2} x_{2}+\cdots+\beta_{n} x_{n}+\varepsilon
$$

where, $\mathrm{y}$ is dependent variable, $\beta_{0}, \beta_{1}, \beta_{2}, \ldots, \beta_{n}$ are regression coefficients, $\mathrm{x}_{\mathrm{i}}{ }^{\prime} s$ are the independent variables in the model and $\boldsymbol{\varepsilon}$ which is the error term.

The matrix of multiple regression analysis is stated as follows [29]:

$$
\left[\begin{array}{c}
y_{1} \\
y_{2} \\
\vdots \\
y_{n}
\end{array}\right]=\left[\begin{array}{ccccc}
1 & x_{11} & x_{12} & \ldots & x_{1 k} \\
1 & x_{21} & x_{22} & \ldots & x_{2 k} \\
\vdots & \vdots & \vdots & \ddots & \vdots \\
1 & x_{n 1} & x_{n 2} & \ldots & x_{n k}
\end{array}\right]\left[\begin{array}{c}
\beta_{0} \\
\beta_{1} \\
\vdots \\
\beta_{k}
\end{array}\right]+\left[\begin{array}{c}
\varepsilon_{1} \\
\varepsilon_{2} \\
\vdots \\
\varepsilon_{n}
\end{array}\right]
$$

The least square estimation of $\beta$ is solved with the least squares formula [30]:

$$
\hat{\beta}=\left(X^{\prime} X\right)^{-1} X^{\prime} Y
$$

The significance of relationship between dependent and independent variables states that at least one $\beta$ parameter diverges from the others.

$$
\begin{aligned}
& \mathrm{H}_{0}: \beta_{l}=\beta_{l}=\ldots \beta_{k}=0 \\
& \mathrm{H}_{\mathrm{a}}: \beta_{j} \neq 0 \text { for at least one } j .
\end{aligned}
$$

Hence, the hypothesis that we have tested using a linear multiple regression method is listed below:

H5: At least one independent (explanatory) variable (exports, investments, investments, research\&innovation) is a significant contributor to the net salary and employment.

- H5.1: At least one independent variable is a significant contributor to the net salary in North Macedonia

- H5.2: At least one independent variable is a significant contributor to the net salary in Serbia.

\section{Results and discussion}

We have tested hypothesis (H5) using a multiple linear regression model in which we have generated two models. The first model was to investigate and analyze whether any of the independent variables (exports, investments, education, and research\&innovation) is a significant contributor to the dependent variable, net salary. In the second model, independent variables were generated as same as in the first model which we have investigated whether any of them is a significant contributor to the employment level. Discussion is analyzed in two parts including North Macedonia and Serbia with an 8-year average data analysis per country. 
$F$-test was the first test that we have performed in our analysis to check whether B2C and B2B sectors have equal/unequal sample variances. Using Microsoft excel we have simulated the ANOVA from the Data Analysis tool. With the level of significance $\alpha=0.05$ we have rejected the null hypothesis and concluded that $\mathrm{B} 2 \mathrm{C}$ and $\mathrm{B} 2 \mathrm{~B}$ sectors have unequal sample variances with as $p$-value is equal to $1.96 \mathrm{E}-04$.

\subsection{Net salaries}

Since $F$-test proved that $\mathrm{B} 2 \mathrm{C}$ and $\mathrm{B} 2 \mathrm{~B}$ sectors have unequal sample variances, the second test to be used was $t$ test assuming unequal sample variances, using Microsoft Excel. In this step, we have analyzed the first comparison hypothesis for both North Macedonia and Serbia. Null Hypothesis (H1) states that B2C is betterpaid sector than B2B. After running the t-test using the Microsoft Excel for both countries, we have inserted the results into the Table 1. where the $p$-value for North Macedonia was 1.37E-21 and for Serbia 3.09E-01.

Table 1. H1: B2C is better-paid sector than B2B - Net Salaries

\begin{tabular}{lccc}
\hline Country & $\begin{array}{c}\text { Mean Difference } \\
\text { (B2B-B2C) }\end{array}$ & $P(T \leq t)$ One-tail & $P(T \leq t)$ Two-tail \\
\hline North Macedonia & -60.18 & $1.37 \mathrm{E}-21$ & $2.74 \mathrm{E}-21$ \\
Serbia & -25.72 & $3.09 \mathrm{E}-01$ & $6.19 \mathrm{E}-01$ \\
\hline
\end{tabular}

Assuming the level of significance $\alpha=0.05$ we fail to reject the null hypothesis and conclude that $\mathrm{B} 2 \mathrm{C}$ sectors are better paid than B2B in North Macedonia and Serbia with a slight mean difference.

\subsection{Employment rate}

The second hypothesis in the Table 2 for the $t$-test indicates that B2C sectors in North Macedonia and Serbia have lower employment rate than B2B. In this analysis we face differences between the two countries.

Table 2. H2: B2C has lower employment rate than B2B - Employment

\begin{tabular}{lccc}
\hline Country & $\begin{array}{c}\text { Mean Difference } \\
(\mathrm{B} 2 \mathrm{~B}-\mathrm{B} 2 \mathrm{C})\end{array}$ & $\mathrm{P}(\mathrm{T} \leq \mathrm{t})$ One-tail & $\mathrm{P}(\mathrm{T} \leq \mathrm{t})$ Two-tail \\
\hline North Macedonia & 379 & $4.78 \mathrm{E}-01$ & $9.57 \mathrm{E}-01$ \\
Serbia & -359940 & $2.18 \mathrm{E}-04$ & $4.35 \mathrm{E}-04$ \\
\hline
\end{tabular}

As it's shown on the table, North Macedonia has the $p$-value 4.78E- 01 which is greater the value of $\alpha=0.05$, hence we fail to reject the null hypothesis and conclude that B2B sectors have higher employment rate. However, $p$-value of 2.18E-04 which is much less than the value of $\alpha=0.05$ in Serbia we reject the null hypothesis and conclude that $\mathrm{B} 2 \mathrm{~B}$ sectors have lower employment rate compared to B2C sectors. It is important to state that, the brain drain phenomenon - where skilled people especially the youth are leaving the countries to other countries for a better job and salary, help two business models to face lower employment. As stated in the introduction, North Macedonia is the second country in the Balkans with the highest number of people leaving the country after Albania in the last ten years.

\subsection{Exports}

Exports play an important role in a country's development and economic growth. Because of that, we have tested the null hypothesis to see if B2C companies are more successful than B2B ones. The results are shown in Table 3.

Table 3. H3: B2C companies are more successful than B2B - Exports

\begin{tabular}{lccc}
\hline \multicolumn{1}{c}{ Country } & $\begin{array}{c}\text { Mean Difference } \\
\text { (B2B-B2C) }\end{array}$ & $P(T \leq t)$ One-tail & $P(T \leq t)$ Two-tail \\
\hline North Macedonia & 4830640100 & $2.60 \mathrm{E}-07$ & $5.19 \mathrm{E}-07$ \\
Serbia & 4811321988 & $3.05 \mathrm{E}-05$ & $2.09 \mathrm{E}+00$ \\
\hline
\end{tabular}

The null hypothesis is stated the same for both countries. After running the $t$-test assuming unequal variances, the $p$-value 2.60E-07 for North Macedonia and the $p$-value 3.05E-05 for Serbia are significantly lower than the $\alpha=0.05$. Here, the results of the null hypothesis give the same conclusion for the above-mentioned countries in which the null hypothesis is rejected. Accordingly, B2B companies are significantly more successful than B2C, with a much higher mean difference than B2C. Serbia is a leading country with the highest export rate in 
the Balkan countries to Germany $12 \%$, Bosnia and Herzegovina $10.1 \%$, making it as $71^{\text {st }}$ largest exporter in the world according to OEC. However, North Macedonia is placed as the $99^{\text {th }}$ largest exporter in the world and the main export partners are Germany, Serbia, Bulgaria, the Czech Republic and Greece.

\subsection{Investments}

The last variable that we have tested using the comparison t-test in both countries was investments. The null hypothesis is stated that B2C companies invest more than B2B in North Macedonia and Serbia and the result are shown in Table 4.

Table 4. H4: B2C companies' investments are higher than B2B - Investment

\begin{tabular}{lccc}
\hline \multicolumn{1}{c}{ Country } & $\begin{array}{c}\text { Mean Difference } \\
(\mathrm{B} 2 \mathrm{~B}-\mathrm{B} 2 \mathrm{C})\end{array}$ & $\mathrm{P}(\mathrm{T} \leq \mathrm{t})$ One-tail & $\mathrm{P}(\mathrm{T} \leq \mathrm{t}) \mathrm{Two}-\mathrm{tail}$ \\
\hline North Macedonia & 242838 & $6.31 \mathrm{E}-03^{*}$ & $1.26 \mathrm{E}-02^{*}$ \\
Serbia & -450199 & $9.37 \mathrm{E}-02^{*}$ & $1.87 \mathrm{E}-01$ \\
\hline *significant at $\alpha=0.05$ & & &
\end{tabular}

*significant at $\alpha=0.05$

Based on the $t$-test result shown in Table 4. there is significant difference in investment in B2B and B2C In North Macedonia and Serbia. The null hypothesis is rejected with the $p$-value 6.31E-03, and state that there is enough significant data that B2B companies invest more in North Macedonia compared to B2C companies. However, in Serbia the null hypothesis is accepted after the positive attempt of the $t$-test in which the $p$-value is 9.37E-02 which is higher than the actual $\alpha=0.05$, therefore we accept the null hypothesis and state that B2C companies invest more in Serbia. The difference is that B2B sectors in North Macedonia invest more compared to B2C sectors, but in Serbia B2C companies invest more than B2B companies.

After the comparison $t$-test using Microsoft Excel, we have performed the multiple regression analysis with the two regression models as follows:

1. Net Salary $=$ Export+Education+Investment+Research\&Innovation

2. Employment $=$ Export + Education+Investment+Research\&Innovation

where, net salary and employment are dependent variables, however export, education, investment and research\&innovaton are independent variables. In this test, we check, for the significant relationship in the model and significant contributor between independent variables, rather than the comparison. Here two tests are being performed. $F$-test is used to analyze whether a significant relationship between the dependent and independent variables occur which is called overall significance. If $F$-test shows an overall significance then $t$ test is used to determine the significant contributor in the independent variables which is called individual significance [27].

Table 5. Results for Net Salary in North Macedonia

\begin{tabular}{lcccc}
\hline & Coefficients & Standard Error & $t$ Stat & $P$-value \\
\hline Intercept (Net Salary) & $3.39 \mathrm{E}+02$ & $6.95 \mathrm{E}+01$ & $4.87 \mathrm{E}+00$ & $8.23 \mathrm{E}-03$ \\
Export & $1.45 \mathrm{E}-08$ & $4.11 \mathrm{E}-09$ & $3.54 \mathrm{E}+00$ & $2.41 \mathrm{E}-02 *$ \\
Investment & $1.47 \mathrm{E}-09$ & $1.52 \mathrm{E}-08$ & $9.66 \mathrm{E}-02$ & $9.28 \mathrm{E}-01$ \\
Education & $-4.53 \mathrm{E}-04$ & $8.17 \mathrm{E}-04$ & $-5.54 \mathrm{E}-01$ & $6.09 \mathrm{E}-01$ \\
Research\&Innovation & $2.91 \mathrm{E}-07$ & $2.91 \mathrm{E}-07$ & $9.99 \mathrm{E}-01$ & $3.74 \mathrm{E}-01$ \\
\hline
\end{tabular}

*significant at $\alpha=0.05$

The first model stated above with the net salary as the dependent variable in North Macedonia to check whether there is a significant relationship between independent variables, if so, at least one the independent variables would be a significant contributor in this country. In multiple linear regression analysis, the multiple $R$ is the coefficient of multiple correlations, where $\mathrm{R}$ square is the coefficient of determination. In this model $R$ square is 0.94 or $94 \%$ in which we are pleased to find such a good model fit for the estimated regression equation. Using the level of significance is $\alpha=0.05$ and the $p$-value for overall significance was $1.09 \mathrm{E}-02$ indicates that we can reject the null hypothesis because the $p$-value is less than $\alpha=0.05$, hence in this model, there is at least one significant contributor related to the net salary. 
Since ANOVA shows that the multiple regression relationship is significant, then we use the $t$-test to determine the significant contributor of each of the individual parameters. When we conducted $t$-test for individual significance among the four independent it shows that only the Export is significant contributor related to the net salary in North Macedonia since $p$-value $=2.41 \mathrm{E}-02$ is less than $\alpha=0.05$, hence we reject the null hypothesis. Since only the Export is significantly related to the Net Salary, the following regression model can be used for estimation the Net Salary:

$$
\text { Net Salary }=3.39 \times 10^{2}+1.45 \times 10^{-8} \text { Export }_{\mathrm{NM}}
$$

However, the other three independent variables Investment, Education, and Research\&Innovation are not significant contributors since their $p$-value is much higher than the significance level, so we cannot estimate any other regression equation model except the Export. Moreover, according to the statistical data, North Macedonia invests very less to the Research\&Innovation, thus cannot be a significant contributor to the response variable, the Net Salary.

Table 6. Results for Employment in North Macedonia

\begin{tabular}{lcccc}
\hline & Coefficients & Standard Error & $t$ Stat & $P$-value \\
\hline Intercept (Employment) & $3.18 \mathrm{E}+05$ & $8.28 \mathrm{E}+04$ & $3.85 \mathrm{E}+00$ & $1.83 \mathrm{E}-02$ \\
Export & $2.66 \mathrm{E}-05$ & $4.89 \mathrm{E}-06$ & $5.45 \mathrm{E}+00$ & $5.52 \mathrm{E}-03 *$ \\
Investment & $7.00 \mathrm{E}-05$ & $1.81 \mathrm{E}-05$ & $3.87 \mathrm{E}+00$ & $1.80 \mathrm{E}-02 *$ \\
Education & $-1.73 \mathrm{E}+00$ & $9.72 \mathrm{E}-01$ & $-1.78 \mathrm{E}+00$ & $1.50 \mathrm{E}-01$ \\
Research\&Innovation & $-2.46 \mathrm{E}-04$ & $3.47 \mathrm{E}-04$ & $-7.08 \mathrm{E}-01$ & $5.18 \mathrm{E}-01$ \\
\hline
\end{tabular}

*significant at $\alpha=0.05$

Applying the same principle for the second model with employment as its dependent variable, some differences can be shown. We were excited to check whether there is a relationship between independent variables and employment as a response variable. We believe that this model has a very strong relationship between independent and dependent variables since the $\mathrm{R}$ square is equal to 0.98 or $97 \%$ which represents a good model fit. Next, with the level of significance $\alpha=0.05$ which is smaller than the $F$-test or overall significance value 1.37E-03, we reject the null hypothesis and we conclude that there is a significant relationship or at least one of independent variables is significant contributor related to the Employment in North Macedonia.

Now, we discuss parameters which significantly contribute to employment. Compared to the first model in which there was only one significant contributor, here there are two variables, Export with the $p$-value 5.52E03 and Investment 1.80E-02 in which both of them significantly contribute to the Employment in North Macedonia. Moreover, since two of the variables are contributors to the response variable - Employment, we bring the following regression models which can be used to estimate the employment in Macedonia:

$$
\text { Employment }=3.18 \times 10^{5}+2.66 \times 10^{-5} \text { Export }_{\mathrm{NM}}+7.00 \times 10^{-5} \text { Investment }_{\mathrm{NM}}
$$

However, education and Research\&Innovation have much higher p-value than the significance level, therefore they are not contributors to the employment level in North Macedonia.

Table 5. Results for Net Salary in Serbia

\begin{tabular}{lcccc}
\hline & Coefficients & Standard Error & $t$ Stat & $P$-value \\
\hline Intercept (Net Salary) & $-8.32 \mathrm{E}+02$ & $4.27 \mathrm{E}+02$ & $-1.95 \mathrm{E}+00$ & $1.23 \mathrm{E}-01$ \\
Export & $2.10 \mathrm{E}-08$ & $5.16 \mathrm{E}-09$ & $4.08 \mathrm{E}+00$ & $1.51 \mathrm{E}-02^{*}$ \\
Investment & $7.92 \mathrm{E}-09$ & $9.87 \mathrm{E}-09$ & $8.02 \mathrm{E}-01$ & $4.67 \mathrm{E}-01$ \\
Education & $4.30 \mathrm{E}-03$ & $1.74 \mathrm{E}-03$ & $2.47 \mathrm{E}+00$ & $6.90 \mathrm{E}-02^{*}$ \\
Research\&Innovation & $2.38 \mathrm{E}-07$ & $1.22 \mathrm{E}-07$ & $1.95 \mathrm{E}+00$ & $1.24 \mathrm{E}-01$ \\
\hline
\end{tabular}

*significant at $\alpha=0.05$

Multiple regression analysis showed that the two regression models as the first having the net salary its dependent variable and the second model with the employment as the dependent variable, both have a significant 
relationship to the independent variables (Export, Education, Investment, and Research\&Innovation) in Serbia as well. In the first model, we have got a very good model fit with R square of 0.95 or $95 \%$. With the level of significance is $\alpha=0.05$ and the $p$-value for overall significance was 4.85E-03 indicates that we can reject the null hypothesis because the $p$-value is less than $\alpha=0.05$, hence in this model, there is a significant relationship between dependent and independent variables.

Since ANOVA proved that this model has a significant relationship, we performed a further analysis with the other test or $t$-test for individual significance among the four parameters. Compared to North Macedonia, in Serbia, too, the export parameter is the one with a significant contributor related to the net salary $p$-value was $1.51 \mathrm{E}-02$. Also, education is nearly a second contributor related to the net salary with its $p$-value $6.90 \mathrm{E}-02$, but still, we cannot say that it's significant since the $p$-value is higher than $\alpha=0.05$. Furthermore, the regression model can be used to estimate the Net Salary, since Export is a significant contributor to it:

$$
\text { Net Salary }=-8.32 \times 10^{2}+2.10 \times 10^{-8} \text { ExportsR }_{\text {SR }}
$$

The other three control variables Investment, Education, and Research\&Innovation are not significant contributors to the Net Salary in Serbia.

Table 6. Results for Employment in Serbia

\begin{tabular}{lcccc}
\hline & Coefficients & Standard Error & $t$ Stat & $P$-value \\
\hline Intercept (Employment) & $4.09 \mathrm{E}+06$ & $1.03 \mathrm{E}+06$ & $3.97 \mathrm{E}+00$ & $1.65 \mathrm{E}-02$ \\
Export & $-2.22 \mathrm{E}-05$ & $1.24 \mathrm{E}-05$ & $-1.79 \mathrm{E}+00$ & $1.48 \mathrm{E}-01$ \\
Investment & $-2.50 \mathrm{E}-06$ & $2.38 \mathrm{E}-05$ & $-1.05 \mathrm{E}-01$ & $9.21 \mathrm{E}-01$ \\
Education & $-1.01 \mathrm{E}+01$ & $4.20 \mathrm{E}+00$ & $-2.41 \mathrm{E}+00$ & $7.38 \mathrm{E}-02$ \\
Research\&Innovation & $2.38 \mathrm{E}-04$ & $2.95 \mathrm{E}-04$ & $8.09 \mathrm{E}-01$ & $4.64 \mathrm{E}-01$ \\
\hline
\end{tabular}

*significant at $\alpha=0.05$

In Table 6, we have used the multiple regression analysis for the second model related to Employment as its dependent variable. Similarly, as the first model, the second one has a significant relationship between parameters and dependent variable. The R square has a value of 0.89 or $89 \%$ which represents the coefficient determination and shows a good model fit. However, Multiple R is 0.94 or $94 \%$ which is the correlation between actual and predicted values of the dependent variable. The overall significance value was $3.45 \mathrm{E}-02$, leading to reject the null hypothesis with $\alpha=0.05$. Interestingly, in this model, we have faced a small change in which none of the parameters is significant contributor to the employment. Similarly, as in North Macedonia, in Serbia Research\&Innovation does not contribute to any of the models, Net Salary and Employment, which indicates that Serbia has to invest more in this field for a country's better development and economic growth.

\section{Conclusion}

The analysis of this paper shows that there are differences between net salaries, total employment, investments, exports, education and research\&innovation within North Macedonia and Serbia. B2C model or business-toconsumer model means that goods and services directly are sold to the consumer. However, B2B or businessto-business states that there is no relationship between goods/services being sold to the consumer immediately, hence is the transfer of them without the interference of consumer. The comparison $t$-test helped us to compare these two business models in both countries testing four hypotheses within net salaries, employment, exports and investments.

Secondly, we have used multiple linear regression analysis to check for the relationship between the dependent and independent variables and here we have added one more independent variable which is research $\&$ innovation. The results show that they are differences between the two business models in the listed countries. However, there is a relationship between the dependent and independent variables on both models in two countries. In the first model, education is the dependent variable and in the second it is employment. In both models, there is a significant relationship between the two countries. The main problem these countries face is the brain drain phenomenon where the highly qualified workers, especially youth, are leaving their countries for a better job and salary.

One of the developmental solutions is Innovation which is one of the most important factors for a company's performance and as well as for a country's development. Secondly, Industry attractiveness is equally important. 
Hiring high performing employees would not only increase productivity and sale, but the company's growth as well. I firmly believe that if these two countries focus on the last two solutions emphasized, they would solve main problem and improve in the two business models, as well as in the country.

\section{References}

[1] A. Collins, "24/7 Innovation: A Blueprint for Surviving and Thriving in an Age of Change," J. Consum. Mark., 2003.

[2] A. Wong, D. Tjosvold, and C. Liu, "Innovation by teams in Shanghai, China: cooperative goals for group confidence and persistence," Br. J. Manag., vol. 20, no. 2, pp. 238-251, 2009.

[3] S. A. Zahra and J. G. Covin, "The financial implications of fit between competitive strategy and innovation types and sources," J. High Technol. Manag. Res., vol. 5, no. 2, pp. 183-211, 1994.

[4] J. T. Mentzer et al., "Defining supply chain management," J. Bus. Logist., vol. 22, no. 2, pp. 1-25, 2001.

[5] I. Sukati, A. B. Hamid, R. Baharun, and R. M. Yusoff, "The study of supply chain management strategy and practices on supply chain performance," Procedia-Social Behav. Sci., vol. 40, pp. 225-233, 2012.

[6] D. Lucking-Reiley and D. F. Spulber, "Business-to-business electronic commerce," J. Econ. Perspect., vol. 15 , no. 1, pp. 55-68, 2001.

[7] A. Gupta, A. Kumar, R. Grewal, and G. L. Lilien, "Within-seller and buyer-seller network structures and key account profitability," J. Mark., vol. 83, no. 1, pp. 108-132, 2019.

[8] J. J. Dahlgaard, G. K. Khanji, and K. Kristensen, Fundamentals of total quality management. Routledge, 2008.

[9] W. E. Deming and D. W. Edwards, Quality, productivity, and competitive position, vol. 183. Massachusetts Institute of Technology, Center for advanced engineering study ..., 1982.

[10] S. Croom, "Restructuring supply chains through information channel innovation," Int. J. Oper. Prod. Manag., 2001.

[11] K. A. Patterson, C. M. Grimm, and T. M. Corsi, "Adopting new technologies for supply chain management," Transp. Res. Part E Logist. Transp. Rev., vol. 39, no. 2, pp. 95-121, 2003.

[12] K. E. Sluyterman, "B2B or B2C?: Dutch approaches towards marketing and the consumer, 1945-1968, with particular attention to Heineken's Brewery," BMGN-The Low Ctries. Hist. Rev., vol. 132, no. 3, pp. 11-36, 2017.

[13] S. Anthony, "The new corporate garage (pp. 44-53)," Sept. Harvard Bus. Rev., 2012.

[14] F. Damanpour and M. Schneider, "Phases of the adoption of innovation in organizations: effects of environment, organization and top managers 1," Br. J. Manag., vol. 17, no. 3, pp. 215-236, 2006.

[15] H. Chesbrough, "Business model innovation: opportunities and barriers," Long Range Plann., vol. 43, no. 2-3, pp. 354-363, 2010.

[16] B. Demil and X. Lecocq, "Business model evolution: in search of dynamic consistency," Long Range Plann., vol. 43, no. 2-3, pp. 227-246, 2010.

[17] M. Sosna, R. N. Trevinyo-Rodríguez, and S. R. Velamuri, "Business model innovation through trialand-error learning: The Naturhouse case," Long Range Plann., vol. 43, no. 2-3, pp. 383-407, 2010.

[18] M. W. Johnson, C. M. Christensen, and H. Kagermann, "Reinventing your business model," Harv. Bus. Rev., vol. 86, no. 12, pp. 57-68, 2008.

[19] D. Mitchell and C. Coles, "The ultimate competitive advantage of continuing business model innovation," J. Bus. Strategy, 2003.

[20] S. Trimi and J. Berbegal-Mirabent, "Business model innovation in entrepreneurship," Int. Entrep. Manag. J., vol. 8, no. 4, pp. 449-465, 2012.

[21] C. M. Christensen, "Marketing strategy: learning by doing," Harv. Bus. Rev., vol. 75, no. 6, pp. 141$151,1997$.

[22] D. J. Teece, "Business models, business strategy and innovation," Long Range Plann., vol. 43, no. 2-3, pp. 172-194, 2010.

[23] G. Stefano, "Perspectives of EU membership for BiH," 2018.

[24] M. K. Pelosi and T. M. Sandifer, Elementary statistics: From discovery to decision. John Wiley \& Sons, 2003.

[25] B. Gerald, "A Brief Review of Independent, Dependent and One Sample t-test," Int. J. Appl. Math. Theor. Phys., vol. 4, no. 2, p. 50, 2018, doi: 10.11648/j.ijamtp.20180402.13.

[26] V. Bewick, L. Cheek, and J. Ball, "Statistics review 9: one-way analysis of variance," Crit. care, vol. 8, 
no. 2 , p. $130,2004$.

[27] P. Edwards, Essentials of Statistics for Business and Economics, vol. 61, no. 2. Cengage Learning, 2007.

[28] D. C. Montgomery, Introduction to statistical quality control. John Wiley \& Sons, 2007.

[29] X. Yan and X. Su, Linear regression analysis: theory and computing. World Scientific, 2009.

[30] R. E. Walpole, R. H. Myers, S. L. Myers, and K. Ye, Probability and statistics for engineers and scientists, vol. 5. Macmillan New York, 1993.

[31] B. Durakovic and A. Cosic, Sustainable Engineering and Innovation, vol. 1, no. 1, p. 24-33, 2019. 